\title{
Intraocular pressure measurement after penetrating keratoplasty: minified Goldmann applanation tonometer, pneumatonometer, and Tono-Pen versus
} manometry

\author{
Mitchel J Ménage, Paul L Kaufman, Mary Ann Croft, Stuart P Landay
}

\begin{abstract}
The accuracy of intraocular pressure measurement with the minified Goldmann applanation tonometer, the pneumatonometer, and the Tono-Pen tonometer were compared in postmortem human eyes which had undergone penetrating keratoplasty. Enucleated postmortem human eyes underwent same sized $(7.75 \mathrm{~mm})$ or $0.5 \mathrm{~mm}$ oversized $(8.25 \mathrm{~mm})$ autologous penetrating keratoplasty. Intraocular pressure was then set and measured manometrically while being determined successively with each tonometer over the range of 0-65 mm $\mathrm{Hg}$. Linear regression analysis comparing tonometric and manometric readings showed: (1) minified Goldmann applanation tonometer - slope $\mathbf{0 . 9 8 5}$ and $\mathbf{0 . 9 4 4}$, intercept 1.64 and $2.55 \mathrm{~mm} \mathrm{Hg}$, correlation coefficient 0.99 and 0.99 in same sized and oversized grafted eyes respectively; (2) pneumatonometer - slope $\mathbf{1 . 0 0 8}$ and $\mathbf{0 . 9 9 0}$, intercept 3.37 and $3.69 \mathrm{~mm} \mathrm{Hg}$, correlation coefficient 0.99 and 0.98 ; (3) Tono-Pen - slope 1.061 and 1.002, intercept 5.01 and $4.06 \mathrm{~mm} \mathrm{Hg}$, correlation coefficient 0.97 and 0.98 . We concluded that the minified Goldmann applanation tonometer is as accurate or more accurate than the pneumatonometer and the Tono-Pen in postmortem post-keratoplasty human eyes, and may be an economical, convenient alternative to the latter two instruments in clinical practice.
\end{abstract}

(Brf Ophthalmol 1994; 78: 671-676)

The measurement of intraocular pressure after penetrating keratoplasty is reported to be difficult with the Goldmann applanation tonometer because of inaccuracy induced by the sutures interfering with the tip of the instrument, corneal surface irregularity, and corneal oedema.' Several authors have shown that there is a marked tendency to high intraocular pressure in the immediate postoperative period, particularly after aphakic or pseudophakic graft surgery. ${ }^{1-3}$ Some patients show a late postoperative chronic elevation of intraocular pressure,,$^{3-5}$ particularly if there is a preoperative history of glaucoma. ${ }^{3}$ Goldmann applanation tonometry is most problematic in the immediate postoperative period and in some cases can remain a long term difficulty. Since the advent of the Mackay-Marg tonometer ${ }^{6}$ and its more modern version, the Tono-Pen, ${ }^{7}$ measurement of intraocular pressure after penetrating keratoplasty is reported to be more reliable. ${ }^{8-10}$ Others have investigated the use of the pneumatonometer ${ }^{11}$ in irregular or recently grafted eyes. ${ }^{12}$

The accuracy of a minified version of the Goldmann applanation tonometer in normal cynomolgus monkey and human eyes has been described.$^{13}$ In this instrument the front $4 \mathrm{~mm}$ of a standard Goldmann applanating prism is reduced in diameter from $7.0 \mathrm{~mm}$ to $4.00 \mathrm{~mm}$ on a lathe, without changing the endpoint of intraocular pressure measurement, which is the applanation of a circle of cornea $3.06 \mathrm{~mm}$ in diameter. The authors suggested that the minified Goldmann applanation tonometer would permit applanation of the central graft tissue, without interference from the sutures or irregular interface tissue, in eyes which have undergone penetrating keratoplasty.

The pneumatonometer, developed by Langham and co-workers, ${ }^{11}$ consists of a hollow plunger in a porous sleeve propelled by gas and using a gas bearing. The tip is $4.4 \mathrm{~mm}$ in diameter and covered with a thin silicone rubber membrane. When the tip is applied to the cornea the membrane occludes multiple small orifices, impeding the outflow of gas and propelling the plunger toward the eye with greater force until equilibrium is reached. At equilibrium the pressure in the flow system is proportional to the intraocular pressure and is measured electronically and displayed either on a liquid crystal panel (Modular One; Mentor O \& O, Inc, Norwell, MA, USA) or as a pen recording (Model $30 \mathrm{R}$; Mentor O \& O). The pneumatonometer was claimed to be an applanation tonometer by Langham but this has been disputed by other investigators. ${ }^{14}$

The Tono-Pen (Mentor $\mathrm{O} \& \mathrm{O}$ ) is a hand held, self-contained instrument which operates on the same principle as the Mackay-Marg tonometer. It consists of a $1.2 \mathrm{~mm}$ central plunger attached to a micro-strain gauge transducer, surrounded by a stationary, nearly flush $3.2 \mathrm{~mm}$ annulus. A disposable tip cover is used to avoid contamination. The force exterted on the plunger is transmitted as a voltage wave that is analysed by a microprocessor for acceptability. Three to six accepted samples are averaged and the mean shown on a liquid crystal display along with a coefficient of variation (standard deviation divided by the mean) indicator.

Both the pneumatonometer and the Tono-Pen are in current clinical use for intraocular pressure measurement after penetrating keratoplasty.

We investigated the accuracy of the minified Goldmann applanation tonometer, pneumatonometer and Tono-Pen in measuring intraocular \\ Accepted for publication
}


pressure characteristics in postmortem human eyes which had received same sized and oversized penetrating corneal grafts.

\section{Materials and methods}

The study used postportem human eyes considered unsuitable for human transplant for various reasons. All experiments were carried out within 48 hours of death. Seven eyes underwent same sized penetrating keratoplasty using a $7 \cdot 75$ $\mathrm{mm}$ hand-held trephine, the button being rotated $90^{\circ}$ and sutured back into place. Seven pairs of eyes underwent a $0.5 \mathrm{~mm}$ oversized penetrating keratoplasty using a $7.75 \mathrm{~mm}$ trephine for the recipient eye and an $8.25 \mathrm{~mm}$ trephine to cut the donor tissue from the paired eye. In all cases the donor tissue was secured with $1610 / 0$ deep stromal nylon sutures in the usual manner. Sutures were not buried but the knots were pulled to the recipient side of the interface. The anterior chambers were reformed using balanced salt solution and if necessary any interface leaks treated by replacement or additional sutures.

Each eye was mounted on a custom built plastic eye holder and secured in position, with the cornea facing horizontally, by pins passed through the optic nerve remnant. The anterior chamber was cannulated through the limbus with a branched 26 gauge needle, one are of which was connected via rigid polyethylene tubing to a vertically adjustable test tube reservoir of degassed mock aqueous humour (Bárány's solution), ${ }^{15}$ the other arm to a pressure transducer, amplifier, and pen recorder. The pressure drop across the needle has previously been calculated to be $0.17 \mathrm{~mm} \mathrm{Hg}$ at $24 \mathrm{~mm} \mathrm{Hg} .{ }^{16}$ A small amount of cyanoacrylate glue was used to seal the entry wound of the needle at the limbus. The transducer was calibrated to $0 \mathrm{~mm} \mathrm{Hg}$, $30 \mathrm{~mm} \mathrm{Hg}$, and $60 \mathrm{~mm} \mathrm{Hg}$ using test tube reservoirs of water before each experiment.

The eye was placed at the calibrated $0 \mathrm{~mm} \mathrm{Hg}$ height, the test tube reservoir raised to a height corresponding to $20 \mathrm{~mm} \mathrm{Hg}$, and the intraocular pressure allowed to stabilise. The central graft tissue thickness was measured using an optical pachymeter (Haag-Streit) and the corneal curvature at the steepest and flattest meridians measured using a keratometer (Bausch \& Lomb, Inc, Rochester, NY, USA).

The intraocular pressure was then measured using the minified Goldmann applanation tonometer (mounted on a standard Goldmann applanation apparatus on a Haag-Streit slitlamp), the pneumatonometer (Modular One), and the Tono-Pen (XL). The instruments were always used in that order and all measurements at all pressures were carried out with one instrument before using another. The manometric pressure was raised in approximately 12 arbitrary increments between $0 \mathrm{~mm} \mathrm{Hg}$ and $65 \mathrm{~mm} \mathrm{Hg}$, with measurements at each level after 60 seconds of stabilisation. The test tube reservoir was open to the eye throughout the experiment.

If the epithelium became oedematous and friable during the experiment, it was carefully scraped from the central graft tissue with a blade. This occurred in five of the seven same sized grafts and three of the seven oversized grafts, always early in the minified Goldmann tonometer measurement series.

Before each experiment, calibration of the minified Goldmann applanation tonometer was tested with the standard metal calibration rod in the usual manner. The scale wheel was dialled to $20 \mathrm{~mm} \mathrm{Hg}$ before and after each intraocular pressure measurement and was masked with a paper strip before determination of each applanation end point. The planed $4 \mathrm{~mm}$ diameter tip was placed precisely within the graft interface on the surface of the graft tissue. To correct for any inaccuracy caused by graft astigmatism, the intraocular pressure was measured with the mires oriented both horizontally and vertically for each manometric pressure and the mean of the readings used for comparison. ${ }^{17}$ 'Half and Half coffee creamer (Borden, Inc, Columbus, Ohio; milk, cream, non-fat dry milk, disodium phosphate, sodium citrate) was used in the tear film instead of fluorescein to generate the mires, since the tendency of fluorescein to infiltrate the corneal epithelium with repeated measurements ${ }^{18}$ made end point determination very difficult. The effect of this substitution on intraocular pressure readings with the Goldmann applanation tonometer should be minimal. The 'Half and Half' was applied directly to the tip of the prism with an eye dropper and cleaned off with alcohol between each measurement.

The pneumatonometer and the Tono-Pen were both supplied by the manufacturer for our experiments. The pneumatonometer was calibrated with the manufacturer's standard test apparatus, which artificially mimics an intraocular pressure of $20 \mathrm{~mm} \mathrm{Hg}$. The plastic tip was placed on the graft tissue within the interface and the digital readout of the intraocular pressure recorded. The surface of the pneumatonometer tip was cleaned with alcohol and dried thoroughly after each measurement.

The calibration procedure for the Tono-Pen was carried out at the beginning of each experiment. The tip of the instrument was applied to the centre of the graft tissue. The latex tip cover was replaced after every second intraocular pressure measurement. The instrument will accept a series of three to six readings and automatically displays the mean intraocular pressure and a coefficient of variation indicator. We only accepted values with a coefficient of variation $\leqslant 5 \%$.

\section{Results}

Details are summarised for the same sized grafts in Table 1 and for the oversized grafts in Table 2. As would be expected ${ }^{19}$ the mean keratometer readings from the same sized grafts were significantly flatter than the oversized grafts $(p=0.002$ unpaired two tailed $t$ test).

The results for the minified Goldmann applanation tonometer, pneumatonometer, and Tono-Pen are summarised in Figures 1, 2, and 3 respectively. There were a total of 81 intraocular pressure measurements in the seven same sized penetrating keratoplasty eyes and 87 in the seven oversized penetrating keratoplasty eyes with the minified Goldmann applanation tonometer, 84 
Table 1 Details of same sized penetrating keratoplasty eyes

\begin{tabular}{|c|c|c|c|c|c|c|}
\hline \multirow{2}{*}{$\begin{array}{l}\text { Donor } \\
\text { no }\end{array}$} & \multirow{2}{*}{$\begin{array}{l}\text { Age } \\
\text { (years) }\end{array}$} & \multirow{2}{*}{$\begin{array}{l}\text { Time from death } \\
\text { to experiment } \\
\text { (hours) }\end{array}$} & \multirow{2}{*}{$\begin{array}{l}\text { Graft thickness } \\
(\mathrm{mm})\end{array}$} & \multicolumn{3}{|c|}{ Keratometry (dioptres) } \\
\hline & & & & Flattest & Steepest & Mean \\
\hline $\begin{array}{l}1 \\
2 \\
3 \\
4 \\
5 \\
6 \\
7 \\
\text { Mean } \\
\text { SD }\end{array}$ & $\begin{array}{r}52 \\
52 \\
71 \\
71 \\
57 \\
57 \\
73 \\
62 \\
9\end{array}$ & $\begin{array}{l}21 \\
24 \\
24 \\
45 \\
14 \\
34 \\
29 \\
27 \\
10\end{array}$ & $\begin{array}{l}0.76 \\
0.80 \\
0.90 \\
0.85 \\
0.70 \\
0.75 \\
0.75 \\
0.79 \\
0.07\end{array}$ & $\begin{array}{r}36 \cdot 0 \\
36 \cdot 3 \\
36 \cdot 5 \\
36 \cdot 0 \\
38 \cdot 5 \\
39 \cdot 5 \\
39 \cdot 5 \\
37 \cdot 5 \\
1.6\end{array}$ & $\begin{array}{r}41 \cdot 5 \\
39 \cdot 5 \\
41 \cdot 0 \\
40 \cdot 5 \\
42 \cdot 0 \\
42 \cdot 5 \\
48 \cdot 0 \\
42 \cdot 1 \\
2 \cdot 8\end{array}$ & $\begin{array}{r}38 \cdot 8 \\
37 \cdot 9 \\
38 \cdot 8 \\
38 \cdot 3 \\
40 \cdot 3 \\
41 \cdot 0 \\
43 \cdot 8 \\
39 \cdot 8 \\
2 \cdot 1\end{array}$ \\
\hline
\end{tabular}

Table 2 Details of oversized penetrating keratoplasty eyes

\begin{tabular}{|c|c|c|c|c|c|c|}
\hline \multirow{2}{*}{$\begin{array}{l}\text { Donor } \\
\text { no }\end{array}$} & \multirow{2}{*}{$\begin{array}{l}\text { Age } \\
\text { (years) }\end{array}$} & \multirow{2}{*}{$\begin{array}{l}\text { Time from death } \\
\text { to experiment } \\
\text { (hours) }\end{array}$} & \multirow{2}{*}{$\begin{array}{l}\text { Graft thickness } \\
(\mathrm{mm})\end{array}$} & \multicolumn{3}{|c|}{ Keratometry (dioptres) } \\
\hline & & & & Flattest & Steepest & Mean \\
\hline 1 & 75 & 33 & 0.85 & $39 \cdot 5$ & $49 \cdot 0$ & $44 \cdot 3$ \\
\hline 2 & 55 & 30 & 0.75 & $40 \cdot 5$ & $42 \cdot 5$ & $41 \cdot 5$ \\
\hline 3 & 76 & 7 & 0.80 & $42 \cdot 5$ & $48 \cdot 5$ & $45 \cdot 5$ \\
\hline 4 & 67 & 25 & 0.70 & $41 \cdot 5$ & 46.0 & $43 \cdot 8$ \\
\hline 5 & 70 & 9 & $0 \cdot 70$ & 39.0 & $45 \cdot 5$ & $42 \cdot 3$ \\
\hline 6 & 64 & 29 & 0.80 & $41 \cdot 5$ & $45 \cdot 3$ & $43 \cdot 4$ \\
\hline 7 & 81 & 33 & 0.70 & $41 \cdot 0$ & 44.5 & $42 \cdot 8$ \\
\hline Mean & 70 & 24 & 0.76 & $40 \cdot 8$ & $45 \cdot 9$ & $43 \cdot 3$ \\
\hline SD & 9 & 11 & 0.06 & $1 \cdot 2$ & $2 \cdot 3$ & $1 \cdot 3$ \\
\hline
\end{tabular}

and 91 with the pneumatonometer, and 85 and 91 with the Tono-Pen. Linear regression analyses of the relations between the measured intraocular pressures and actual manometric intraocular pressures are summarised in each figure.

From Figure 1 it can be seen that the minified Goldmann applanation tonometer gave a very

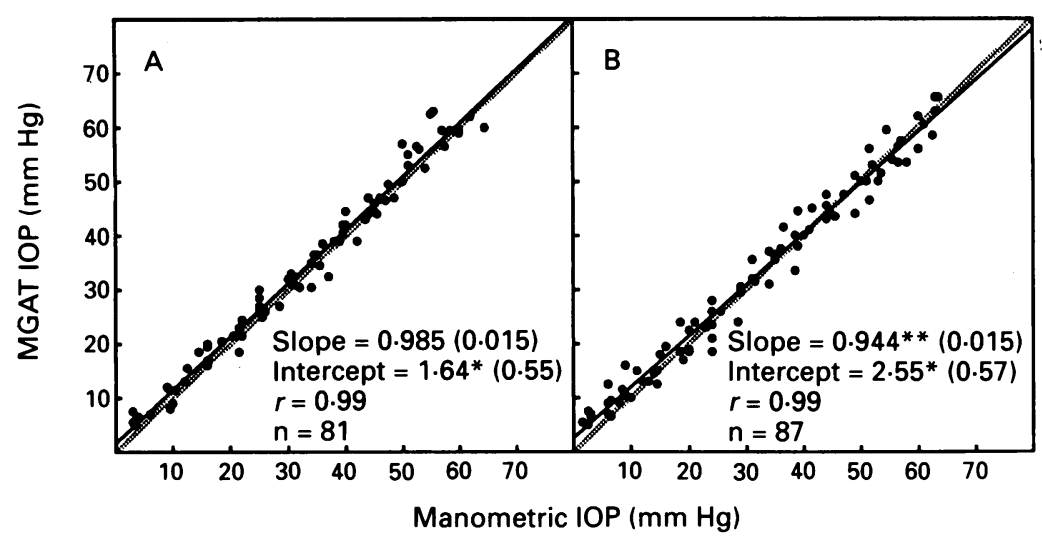

Figure 1 Manometric $(x)$ versus minified Goldmann tonometric $(M G A T ; y)$ intraocular pressure $(I O P)$ measurements in enucleated postmortem human eyes following same size $(A)$ or $0.5 \mathrm{~mm}$ oversized $(B)$ penetrating keratoplasty. Broken line, $y=x$; solid line, least squares regression of MGAT measurements on manometric IOP. $\star \star$ Slope significantly different from $1 \cdot 0, p<0 \cdot 001$. ${ }^{\star}$ Intercept significantly different from $0 \cdot 0, p<0 \cdot 004$. reliable measurement of the intraocular pressure after penetrating keratoplasty in both the same sized and oversized penetrating keratoplasty eyes. The slopes are very close to one with a low intercept and a high correlation coefficient.

From Figures 2 and 3 it can be seen that although both the pneumatonometer and the Tono-Pen gave a reasonable estimate of the manometric intraocular pressure with high correlation coefficients, there was a tendency for both instruments to overread in a linear fashion throughout the range of measurements and this was most pronounced for the Tono-Pen measurements in the eyes with same sized penetrating keratoplasty.

Because of the possibility that the overestimation of intraocular pressure of the pneumatonometer and Tono-Pen could be due to a calibration fault we also tested a second model of each instrument.

The second pneumatonometer (Model $30 \mathrm{R}$ ) had been serviced recently by the manufacturer and was used to measure the intraocular pressure in three of the same sized grafted eyes. Results of a total of 38 separate measurements are graphically summarised in Figure 2C with linear regression analysis. Comparison of Figure 2C with Figure 2A shows that the second instrument also tended to overread, although this effect diminished with increasing pressure.

The second Tono-Pen was in clinical use and was used to measure the intraocular pressure in three of the oversized grafted eyes. The results of 39 separate measurements are graphically summarised in Figure $3 \mathrm{C}$ with linear regression analysis. Comparison of Figure $3 \mathrm{C}$ with Figure 3B shows a very similar overread of intraocular pressure throughout the range of measurements.

Removal of the corneal epithelium changed the slope or intercept in a few instances, but did not alter the overall findings (Table 3 ).

\section{Discussion}

We found the minified Goldmann applanation tonometer to be very accurate in the measurement of the intraocular pressure in both same sized and oversized grafted postmortem human eyes. Minified Goldmann applanation tonometer values reflected manometric intraocular pressure more closely and uniformly across the entire experimental range than the values of the

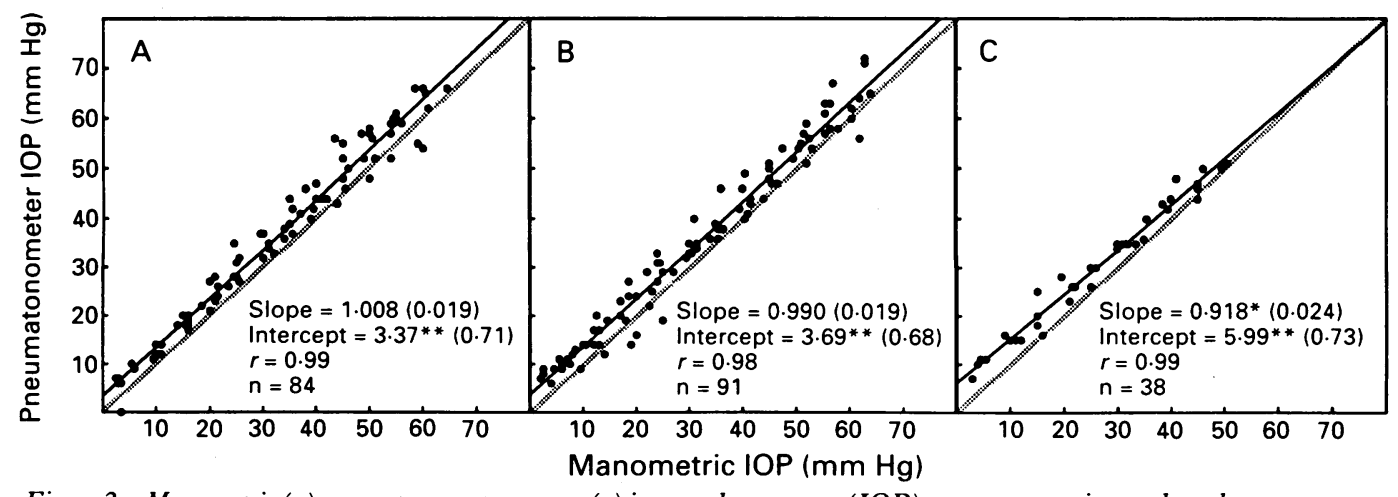

Figure 2 Manometric $(x)$ versus pneumatonometer $(y)$ intraocular pressure $(I O P)$ measurements in enucleated postmortem human eyes following same size (A, pneumatonometer $1 ; C$, pneumatonometer 2$)$ or $0.5 \mathrm{~mm}$ oversized $(B$, pneumatonometer 1$)$ penetrating keratoplasty. Broken line, $y=x$; solid line, least squares linear regression of pneumatonometric measurements on manometric IOP. $\star$ Slope significantly different from $1 \cdot 0, p<0 \cdot 005$. $\star \star$ Intercept significantly different from $0 \cdot 0, p<0 \cdot 0009$. 


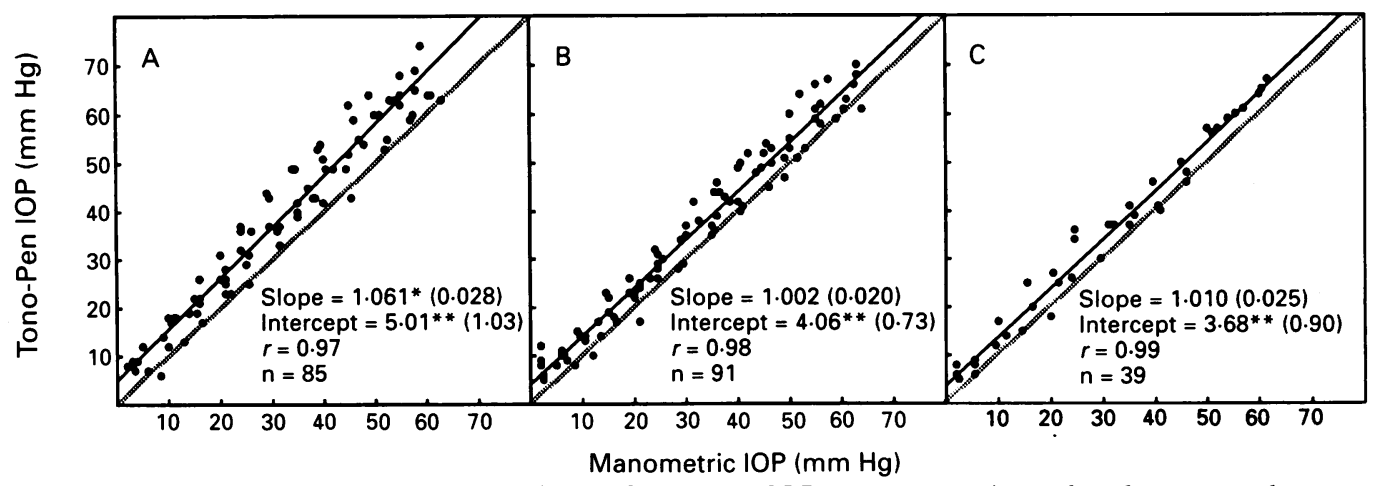

Figure 3 Manometric $(x)$ versus Tono-Pen $(y)$ intraocular pressure $(I O P)$ measurements in enucleated postmortem human eyes following same size (A, Tono-Pen 1 ) or $0.5 \mathrm{~mm}$ oversized ( $B$, Tono-Pen 1; $C$, Tono-Pen 2 ) penetrating keratoplasty. Broken line, $y=x$; solid line, least squares regression of Tono-Pen measurements on manometric IOP. ${ }^{\star}$ Slope significantly different from $1 \cdot 0, p<0.05$. ${ }^{\star}$ Intercept significantly different from $0 \cdot 0, p<0.0009$.

pneumatonometer or Tono-Pen. This was still true when we tested second units of the other instruments.

The much reduced diameter of the tip of the minified Goldmann applanation tonometer allows accurate placement in the centre of the graft tissue, where there is the least irregularity and very little interference with the mires from the sutures or the interface area. The graft diameters we used were large and the minified Goldmann applanation tonometer might be more difficult to use in very small grafts. The more viscous 'Half and Half' also provided slightly broader and more regular mires than ordinary fluorescein.

The minified Goldmann applanation tonometer was certainly the most difficult of the three instruments to use, requiring considerable practice by an operator already very experienced in the use of a conventional Goldmann applanation tonometer. By trial and error we found the best mires were formed by applying the 'Half and Half' direct to the tip of the prism with an eye dropper and cleaning the tip with alcohol between each measurement.

Previous authors have suggested that in the presence of corneal oedema Goldmann applanation tonometry is grossly inaccurate, markedly understimating the true intraocular pressure. ${ }^{182021}$ Moses $^{18}$ found an underestimation of intraocular pressure in an enucleated human eye 33 hours post mortem and attributed the inaccuracy to corneal thickening, although only eight measurements in one eye are shown. Goldmann and Schmidt, ${ }^{22}$ however, found it accurate in postmortem human eyes with slight corneal oedema. Kaufman ${ }^{21}$ postulated that the inaccuracy is caused by the oedematous corneal epithelium being easier to applanate, giving a falsely low estimate of the intraocular pressure. Several of the eyes used in our experiments were 33 or more hours post mortem and there was unquestionably corneal oedema of the graft tissue as judged from the appearance and the elevated pachymetry measurements. One explanation for our improved results was that we removed the corneal epithelium if it became friable and tattered with repeated measurement, providing a smooth surface for the determination of the applanation end point. This occurred in eight of the 14 eyes studied (five of seven same sized and three of seven oversized grafts). Since epithelial removal was always done early in the minified Goldmann measurement series, and since the Goldmann measurements always preceded the pneumatonometer and Tono-Pen measurements, it seemed unlikely that epithelial removal would bias our measurements in favour of the Goldmann apparatus in these eyes. Indeed, although there were some statistically significant differences between slopes or intercepts with and without the corneal epithelium present in a few of the tonometer/graft size subcategories, the overall conclusion was unchanged. A smooth corneal surface is more important for precise measurement with the Goldmann tonometer than with the other two, and in a clinical situation the removal of corneal epithelium after penetrating keratoplasty would normally be precluded, as it would be detrimental to healing. However, in a clinical situation dozens of measurements would not be made within a few minutes, so the epithelium would be far less likely to become so oedematous, friable, or tattered. Although a severely oedematous or irregular corneal graft might compromise measurements with the

Table 3 Regression analysis of tonometry data in same sized and oversized corneal grafts with epithelium intact and removed

\begin{tabular}{|c|c|c|c|c|c|c|c|c|c|c|c|c|}
\hline & \multicolumn{4}{|c|}{$M G A T$} & \multicolumn{4}{|c|}{ Pneumatonometer No 1} & \multicolumn{4}{|c|}{ Tono-Pen No 1} \\
\hline & \multicolumn{2}{|c|}{ Same sized } & \multicolumn{2}{|c|}{ Oversized } & \multicolumn{2}{|c|}{ Same sized } & \multicolumn{2}{|c|}{ Oversized } & \multicolumn{2}{|c|}{ Same sized } & \multicolumn{2}{|c|}{ Oversized } \\
\hline & Intact & Removed & Intact & Removed & Intact & Removed & Intact & Removed & Intact & Removed & Intact & Removed \\
\hline $\begin{array}{l}\text { Slope } \\
\text { SEM } \\
\text { Intercept } \\
\text { SEM } \\
r \\
\text { n }\end{array}$ & $\begin{array}{l}0.996 \\
0.019 \\
1.52^{\mathrm{b}} \\
0.63 \\
1.00 \\
23\end{array}$ & $\begin{array}{c}0.983 \\
0.020 \\
1.65^{b} \\
0.73 \\
0.99 \\
58\end{array}$ & $\begin{array}{c}0.974^{\mathrm{f}} \\
0.016 \\
2.55^{\mathrm{d}} \\
0.59 \\
0.99 \\
52\end{array}$ & $\begin{array}{l}0.909^{d} \\
0.024 \\
2.38^{\mathrm{b}} \\
0.90 \\
0.99 \\
35\end{array}$ & $\begin{array}{l}0.901^{\mathrm{d}, \mathrm{B}} \\
0.023 \\
4.68^{\mathrm{d}} \\
0.83 \\
0.99 \\
25\end{array}$ & $\begin{array}{l}1.049^{\mathrm{b}} \\
0.021 \\
2.90^{\mathrm{d}} \\
0.76 \\
0.99 \\
59\end{array}$ & $\begin{array}{c}1.028^{\mathrm{f}} \\
0.022 \\
3 \cdot 33^{\mathrm{d}} \\
0 \cdot 80 \\
0.99 \\
52\end{array}$ & $\begin{array}{l}0.942^{\mathrm{b}} \\
0.028 \\
4 \cdot 17^{\mathrm{d}} \\
1.05 \\
0.98 \\
39\end{array}$ & $\begin{array}{l}1.042 \\
0.071 \\
4.60^{\mathrm{a}} \\
2.58 \\
0.95 \\
25\end{array}$ & $\begin{array}{l}1.069^{\mathrm{b}} \\
0.027 \\
5.17^{\mathrm{d}} \\
1.00 \\
0.99 \\
60\end{array}$ & $\begin{array}{c}1.017 \\
0.026 \\
4.94^{\mathrm{d}, \mathrm{e}} \\
0.93 \\
0.99 \\
51\end{array}$ & $\begin{array}{l}0.998 \\
0.025 \\
2.59^{c} \\
0.95 \\
0.99 \\
40\end{array}$ \\
\hline
\end{tabular}

Slope significantly different from 1.0 or intercept significantly different from 0.0 by the two tailed paired $t$ test: ${ }^{\mathrm{a}} \mathrm{p}<0.10 ;{ }^{\mathrm{b}} \mathrm{p}<0.05 ;{ }^{\mathrm{c}} \mathrm{p}<0.01 ;{ }^{\mathrm{d}} \mathrm{p}<0.001$. Significantly different from slope or intercept for eyes with corneal epithelium removed, by the two tailed two sample $t$ test: ${ }^{e} \mathrm{p}<0 \cdot 10 ;{ }^{\mathrm{p}} \mathrm{p}<0.05 ;{ }^{\mathrm{g}} \mathrm{p}<0 \cdot 001$. 
minified Goldmann tonometer, the instrument is probably suitable for many, if not most, postkeratoplasty eyes.

We performed and reported keratometry measurements only to define our material. The measurements were not used to guide tonometer orientation or in data analysis, but could be used for the former. ${ }^{17}$

Since modern ophthalmic offices are already equipped with conventional slit-lamp mounted Goldmann applanation tonometers, the lathed minified Goldmann applanation tonometer prism is easily the cheapest of the three instruments. When mounted on a slit-lamp, the minified Goldmann applanation tonometer is less portable than the pneumatonometer and, particularly, the Tono-Pen, and unlike the latter instruments would not allow the intraocular pressure measurement in any position other than at the slit-lamp - for example, lying flat. This problem would be overcome by mounting the minified Goldmann applanation tonometer prism on a Perkins hand held applanation tonometer $^{23}$ or by using a Draeger unit with minified tip. ${ }^{24}$

Both the pneumatonometer and the Tono-Pen tended to overestimate the intraocular pressure in our grafted postmortem eyes, and this was confirmed for a second unit of each instrument. The pneumatonometer can be difficult to use in recently grafted living eyes ${ }^{12}$ and overestimates the intraocular pressure in manometric experiments in postmortem eyes. ${ }^{25}$ In some previous studies, the instrument overestimated low intraocular pressures and underestimated high pressures, ${ }^{14} 26$ or showed a tendency to overestimate intraocular pressure throughout the range tested, when compared with standard Goldmann applanation tonometry. ${ }^{27}$

The Tono-Pen is a modern development of the Mackay-Marg tonometer, which is no longer commercially available. The Tono-Pen is reported to be as accurate as the Mackay-Marg tonometer in measuring intraocular pressure after keratoplasty, ${ }^{10}$ and the Mackay-Marg has been shown previously to be accurate after penetrating keratoplasty ${ }^{189}$ or in the presence of corneal irregularity or oedema. ${ }^{202128}$

The Tono-Pen has been directly compared with the Goldmann applanation tonometer in postmortem ${ }^{2526}$ and living human eyes, ${ }^{7630-32}$ and tended to overestimate low intraocular pressures and underestimate high pressures in all but two studies. A comparative study in postmortem human eyes reported accurate measurement throughout the range of intraocular pressures. ${ }^{25}$ However, this was based on a mean of five separate pressure measurements at only five manometric pressures between 10 and $50 \mathrm{~mm} \mathrm{Hg}$. A recent study comparing the TonoPen with the Goldmann applanation tonometer in normal and grafted human eyes reported significant overestimation of intraocular pressure by the Tono-Pen throughout the range of intraocular pressures, when compared with the Goldmann applanation tonometer readings. ${ }^{32}$ This was more pronounced in the eyes which had undergone penetrating keratoplasty.

Our study also showed a linear overestimation of intraocular pressure after penetrating kerato- plasty by both of the Tono-Pen units, throughout the range of manometric pressures tested. It seems unlikely that both units of the instrument would be incorrectly calibrated.

Clinicians should be aware of the $3-6 \mathrm{~mm} \mathrm{Hg}$ average overestimation of intraocular pressure after penetrating keratoplasty by the Tono-Pen and the pneumatonometer.

We used an open stopcock manometric system to evaluate the accuracy of the instruments, since intraocular pressure remains stable throughout the measurement. Closed stopcock manometry would have mimicked in vivo conditions more closely but is technically more difficult, since intraocular pressure begins to fall as soon as the stopcock is closed, and rises when the tonometer is placed in the eye. ${ }^{1325}$ This is a particular problem when repeated measurements at one manometric pressure are required - for instance, two for the minified Goldmann applanation tonometer and as many as six for the Tono-Pen. These confounding effects can be managed with some effort, ${ }^{13}$ which did not seem warranted here since the magnitudes and measurement consequences of aqueous humour displacement by all three tonometers are already known. ${ }^{131433}$

This study was supported by National Eye Institute grant EY02698. Dr Ménage was supported in part by Bristol and Weston Health Authority and an Ethicon Award from the College of Ophthalmologists. Tono-Pen unit 1 and Pneumatonometer unit 1 were graciously loaned to us by Mentor O \& O, Inc.

1 Irvine AR, Kaufman HE. Intraocular pressure following penetrating keratoplasty. Am $\mathcal{F}$ Ophthalmol 1969; 68: 835-44.

2 Wood TO, West C, Kaufman HE. Control of intraocular pressure in penetrating keratoplasty. Am F Ophthalmol 1972; 74: 724-7.

3 Zimmerman TJ, Olson R, Waltman S, Kaufman HE. Transplant size and elevated intraocular pressure postkeratoplasty. Arch Ophthalmol 1978; 96: 2231-3.

4 Olson RJ, Kaufman HE. Prognostic factors of intraocular pressure after aphakic keratoplasty. Am $\mathcal{F}$ Ophthalmol 1978; 86: $510-5$.

5 Simmons RB, Stern RA, Teekhasaenee C, Kenyon KR. Elevated intraocular pressure following penetrating keratoplasty. Trans Am Ophthalmol Soc 1989; 87: 79-91.

6 Mackay RS, Marg E. Fast, automatic, electronic tonometers based on an exact theory. Acta Ophthalmol 1959; 37: 495-507.

7 Minckler DS, Baerveldt G, Heuer DK, Quillen-Thomas B, Walonker AF, Weiner J. Clinical evaluation of the Oculab Tono-Pen. Am f Ophthalmol 1987; 104: 168-73

8 Wind CA, Irvine AR. Electronic applanation tonometry in corneal edema and keratoplasty. Invest Ophthalmol 1969; 8: $620-4$.

9 Wind CA, Kaufman HE. Validity of Mackay-Marg applanation tonometry following penetrating keratoplasty in man. Am F Ophthalmol 1971; 72: 117-8.

10 Rootman DS, Insler MS, Thompson HW, Parelman J, Poland D, Unterman SR. Accuracy and precision of the Tono-Pen in measuring intraocular pressure after keratoplasty and 1988; 106: 1697-700.

11 Langham ME, McCarthy E. A rapid pneumatic applanation tonometer. Comparative findings and evaluation. Arch Ophthalmol 1968; 79: 389-99.

12 West CE, Capella JA, Kaufman HE. Measurement of intraocular pressure with a pneumatic applanation tonometer. Am $\mathcal{F}$ Ophthalmol 1972; 74: 505-9.

13 Kaufman PL, Davis GE. 'Minified' Goldmann applanating prism for tonometry in monkeys and humans. Arch Ophthalmol 1980; 98: 542-6.

14 Moses RA, Grodzki Jr WJ. The Pneumatonograph. A laboratory study. Arch Ophthalmol 1979; 97: 547-52.

15 Bárány $\mathrm{EH}$. Simultaneous measurement of changing intraocular pressure and outflow facility in the vervet monkey by constant pressure infusion. Invest Ophthalmol Vis Sci 1964; 3: $135-43$.

16 Sponsel WE, Kaufman PL, Strinden TI, DePaul KL, Bowes $\mathrm{HN}$, Olander $\mathrm{KW}$, et al. Evaluation of the Keeler Pulsair non-contact tonometer. Acta Ophthalmol 1989; 67: 567-72.

17 Holliday JT, Allison ME, Prager TC. Goldmann applanation tonometry in patients with regular corneal astigmatism. Am F Ophthalmol 1983; 96: 90-3.

18 Moses RA. The Goldmann applanation tonometer. Am 7 Ophthalmol 1958; 46: 865-69.

19 Heidemann DG, Sugar A, Meyer RF, Musch DC. Oversized donor grafts in penetrating keratoplasty. A randomized trial. Arch Ophthalmol 1985; 103: 1807-11. 
20 MacMillan F, Forster RK. Comparison of Mackay-Marg, Goldmann and Perkins tonometers in abnormal corneas. Arch Ophthalmol 1975; 93: 1420-4.

21 Kaufman HE. Pressure measurement: which tonometer? Invest Ophthalmol Vis Sci 1972; 11: 80-5.

22 Goldmann H. Applanation tonometry. In: Newell FW, ed. Second Fosiah Macy fr Foundation Conference on Glaucoma, New York, Josiah Macy Jr Foundation, 1957: 186-7.

23 Perkins ES. Hand-held applanation tonometer. Brf Ophthalmol 1965; 49: 591-3.

24 Hahnenberger RW. Applanation tonometry in the conscious cynomolgus monkey (Macaca fascicularis). Acta Ophthalmol 1976; 54: 311-9.

25 Mendelsohn AD, Forster RK, Mendelsohn SL, Dennis JJ, Heideman DG, Levine IK. Comparative tonometric measurements of eye bank eyes. Cormea 1987; 6: 219-25. 26 Boothe WA, Lee DA, Panek WC, Pettit TH. The Tono-Pen. A manometric and clinical study. Arch Ophthalmol 1988; 106: 1214

27 Quigley HA, Langham ME. Comparative intraocular pressure measurements with the Pneumatonograph and Goldmann

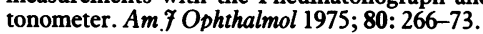

28 Kaufman HE, Wind CE, Waltman SR. Validity of Mackay-Marg electronic applanation in patients with scarred irregular corneas. Am $\mathcal{F}$ Ophthalmol 1970; 69: 1003-7.

29 Hessemer V, Rossler R, Jacobi KW. Comparison of intraocular pressure measurements with the Tono-Pen vs manometry in humans shortly after death. Am $\mathcal{f}$ Ophthalmol 1988; 105: 1678-82.

30 Kao SF, Lichter PR, Bergstrom TJ, Rowe S, Musch DC. Clinical comparison of the Oculab Tono-Pen to the Goldmann applanation tonometer. Ophthalmology 1987; 94: 1541-4.

31 Frenkel REP, Hong YJ, Shin DH. Comparison of the TonoPen to the Goldmann applanation tonometer. Arch OphthalPen to the Goldmann applanation tonometer. Arch Ophthal-
mol 1988; 106: 750-3.

32 Geyer C, Mayron Y, Lowenstein A, Neudorfer $M$, Rothkoff L, Lazar M. Tono-Pen tonometry in normal and post-keratoplasty eyes. $\mathrm{Br} \mathcal{f}$ Ophthalmol 1992; 76: 538-40.

33 Whitacre MC, Emig M, Hassanein K. The effect of Perkins, Tono-Pen, and Schiotz tonometry on intraocular pressure. Am f Ophthalmol 1991; 111: 59-64. 